\title{
ASPECTOS DA ARBORIZAÇÃO URBANA DO CENTRO DE COSMÓPOLIS -SP
}

\author{
Ary Vieira de Paiva ${ }^{1}$
}

(recebido em 31.03.2009 e aceito para publicação em 28.12.2009)

\section{RESUMO}

O presente trabalho foi desenvolvido em Cosmópolis - SP, localizado entre as coordenadas geográficas de $22^{\circ} 38^{\prime} \mathrm{S}$ e $47^{\circ} 10^{\prime} \mathrm{W}$, sob clima Cwa (Köppen), com temperatura média anual de $21,8^{\circ} \mathrm{C}$ e precipitação média anual de $1259 \mathrm{~mm}$.Os objetivos do projeto foram a realização do inventário e diagnóstico da arborização viária urbana localizada no centro do município. A metodologia estatística utilizada foi definida tomando-se como unidade amostral o quarteirão (amostragem casual simples). Foram encontradas 40 espécies diferentes de árvores e quando comparado ao encontrado em outras cidades do Estado de São Paulo foi considerado alto, apresentando IDS de 3,89. A frequencia dos indivíduos por espécie foi muito desuniforme. A quantidade de árvores encontrada por km de calçada foi de 58,93 indivíduos. A altura média das árvores foi de 4,9 $\mathrm{m}$. As espécies de árvores exóticas eram dominantes, representando $57,5 \%$ do total. Os danos causados às calçadas aumentaram com o aumento do porte das árvores, mas a porcentagem dos indivíduos que danificavam as calçadas era baixa. A maioria das árvores (64\%) apresentava algum grau de deformação de copa, sendo que $22 \%$ delas estavam com suas copas irreversivelmente deformadas.

Palavras-chave: árvores, inventário, diagnóstico de árvores, silvicultura urbana

\footnotetext{
${ }^{1}$ Engenheiro agrônomo, Doutor em Recursos Florestais, Universidade Federal do Acre - UFAC, Centro de Ciências Biológicas e da Natureza ; e-mail: <aryvieira1@hotmail.com.br >.
} 


\title{
URBAN FOREST ASPECTS IN CENTRAL ÁREA OF COSMOPOLIS CITY
}

\begin{abstract}
This work was developed in Cosmopolis,SP, located between the geographic coordinates of $22^{\circ} 38^{\prime} \mathrm{S}$ and $47^{\circ} 10^{\prime} \mathrm{W}$, in Cwa climate (Köppen), with average annual temperature of $21.8^{\circ}$ $\mathrm{C}$ and average annual rainfall of $1259 \mathrm{~mm}$. The project objectives were the elaboration of the inventory and diagnosis of sidewalks urban forest located in the center of the city. The statistical methodology used was defined using as the sampling unit the block (simple random sampling). We have found 40 different species of trees and when compared to that found in other cities of the State of São Paulo was considered high, with IDS 3.89. The individual frequency per specie was very uneven. The number of trees found per $\mathrm{km}$ of sidewalks was 58.93.The species of exotic trees were dominant, representing $57.5 \%$ of the total. Damage to sidewalks increased with the increase the tree size, but the percentage of individuals that were damaging the sidewalks was low. Most of the trees (64\%) was with some degree of crown deformation, and $22 \%$ of them were with their crown irreversibly deformed.
\end{abstract}

Keywords: trees, inventory, diagnosis of tree, arboriculture 


\section{INTRODUÇÃO}

A arborização urbana é um equipamento público vivo, prestador de serviços que, segundo Biondi e Althaus (2005), promovem à população conforto ambiental, bem estar psicológico, além da melhoria de aspectos estéticos urbanos, através de uma paisagem mais aprazivel, melhorando a qualidade de vida de seus habitantes. Paiva e Gonçalves (2002) afirmam que "A vegetação urbana contribui para harmonia da paisagem quebrando a dureza e a rigidez do concreto, criando linhas mais suaves e naturais". Arborização urbana não significa apenas plantar árvores em vias públicas, mas integrá-las ao ambiente urbano, compatibilizando-as com os espaços restritos e demais equipamentos públicos existentes (MILANO, 1987). Mas para que possa proporcionar estes benefícios, a arborização urbana deve ser adequadamente planejada em sua concepção, implantação e manejo (MILLER, 1996).

Um planejamento adequado passa pelo pleno conhecimento das características qualiquantitativas da arborização urbana, para possibilitar a realização de intervenções com maiores chances de sucesso. Uma condição indispensável ao planejamento é a realização de um inventário da arborização, para servir de base à elaboração um diagnóstico da mesma. Os inventários podem ser censitários ou amostrais (MILLER, 1996; COUTO e RACHID, 1999).

A escolha das espécies adequadas deve ser baseada tanto em suas características estruturais e estéticas (porte, arquitetura de copa, características físicas da madeira, morfologia e cor de folhas, cor das flores, textura, relação DAP e porte, estrutura e profundidade de raízes, aspectos do tronco, como cor, ritidoma, presença de acúleos e espinhos), como ecológicas (fenologia, estatos sucessional e ciclo de vida, adaptabilidade climática, tolerância ou resistência a pragas e doenças, tolerância ao estresse urbano, tolerância a sombra, tolerância a danos físicos e podas) químicas (princípios alergênicos e tóxicos) e genéticas (diversidade intra-específica, resistência). Milano (1987) afirma também que as características do solo devem ser observadas, pois podem constituir limitações ao desenvolvimento das árvores. A disponibilidade de material propagativo e mudas das espécies recomendáveis também devem ser considerados segundo Gonçalves (2004).

Os objetivos do projeto foram a realização do inventário e diagnóstico da arborização viária urbana localizada no centro do município.

Os estudos sobre a arborização urbana no centro do município de Cosmópolis iniciaram em 2004, estendendo-se até 2005. Por não existir um plano de arborização nem dados técnicos sistematizados, este trabalho foi fundamental para balizar intervenções adequadas na vegetação urbana. 


\section{MATERIAL E MÉTODOS}

O trabalho foi desenvolvido no centro do município de Cosmópolis, interior do Estado de São Paulo (Figura 1), a $138 \mathrm{~km}$ da Capital, localizada entre as coordenadas geográficas de $22^{\circ} 38^{\prime}$ de Latitude Sul e $47^{\circ} 10^{\prime}$ de Longitude Oeste, na macro região de Campinas, encontrando-se na província geomorfológica da Depressão Periférica, tendo clima Cwa (Köppen) com temperatura média anual de $21,8^{\circ} \mathrm{C}$ e precipitação média anual de $1.259 \mathrm{~mm}$ (PRADO, 1997).

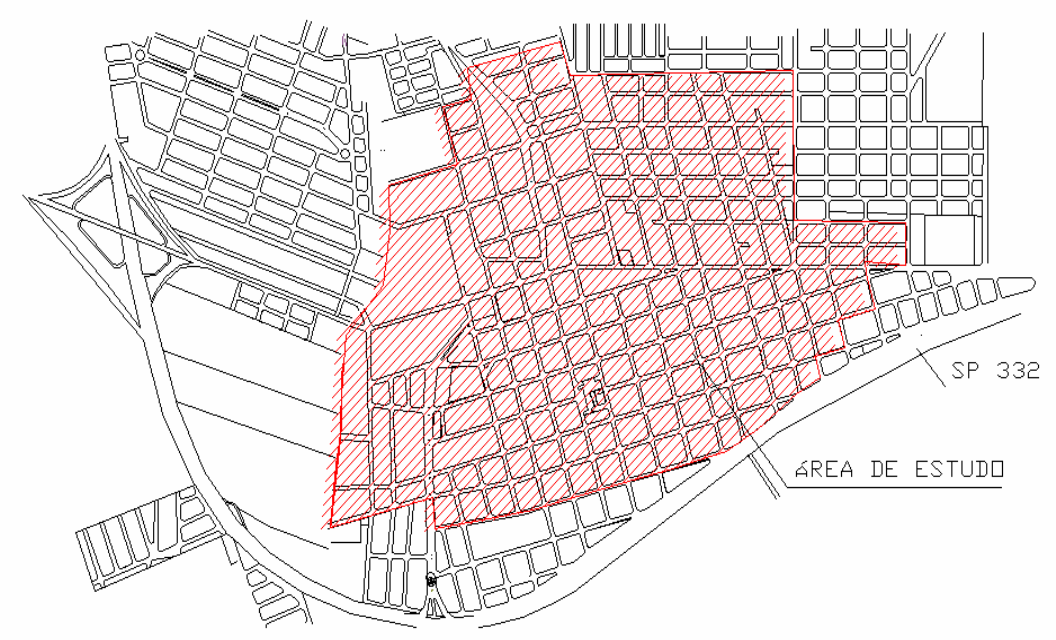

Figura 1. Área de estudo na região central de Cosmópolis, SP.

Estão presentes no município, latossolos roxo distrófico, vermelho escuro álico, vermelho amarelo álico, húmico, argissolo (antigo podizólico) vermelho amarelo álico, cambissolo distrófico, litólico e glei pouco húmico (PRADO, 1997).

Sua cobertura vegetal natural é constituída por floresta latifoliada mesófila semidecídua, cerrado, cerradão e formações higrófilas, em um enclave florístico no bioma mata atlântica.

Seu relevo varia de plano, suavemente ondulado a ondulado e é banhado pelos rios Jaguarí, Pirapitingüi e Ribeirão Três Barras, tributários da bacia hidrográfica do Rio Piracicaba.

Neste trabalho, a base cartográfica utilizada foi uma planta atualizada da malha urbana, em CAD, onde foram marcadas as áreas com arborização mais homogênea, definidas a partir das épocas de consolidação dos bairros e de observações em campo, totalizando 155 quarteirões. O total de quilômetros de calçada foi medido em planta, considerando-se a área total amostrada. 
A metodologia estatística utilizada foi definida tomando-se como unidade amostral o quarteirão (amostragem casual simples), recomendada por Couto e Rachid (1999) e Miller (1996), demonstrando ser a mais adequada e prática. Primeiramente, realizou-se uma préamostragem, considerando-se a quantidade de árvores existentes em 5 quarteirões aleatoriamente escolhidos na área central da cidade (a de consolidação mais antiga). Com estes dados, definiu-se o tamanho ideal da amostra, ou seja, o número de quarteirões necessário para fornecer dados com erro estatístico menor do que $15 \%$, através da fórmula $\mathrm{n}=\mathrm{t}^{2} \cdot \mathrm{N}$. (cv) ${ }^{2} /(\mathrm{ed}) \cdot \mathrm{N}+\mathrm{t}^{2} \cdot(\mathrm{cv})^{2}$, sendo $\mathrm{n}$ o número ideal de amostras, $\mathrm{N}$ o número total de quarteirões; cv o coeficiente de variação definido pela razão porcentual entre o desvio padrão e a média de árvores por quarteirão; ed erro desejável e $t$ distribuição de student (tabela). Definido o número ideal de quarteirões, os mesmos foram aleatoriamente escolhidos na mesma área, somando 17 unidades.

Os parâmetros (variáveis) observados nas árvores foram espécie, identificadas em campo e confirmadas em escritório através de Lorenzi (1998) e Santin (2008), quantidade de indivíduos por espécie, altura, DAP (diâmetro a altura do peito $=1,30 \mathrm{~m}$ ), estado físico da copa e danos à calçada. A altura foi medida com estaca ou por inferência considerando as alturas conhecidas das redes de telefonia e de energia elétrica (secundária e primária). $O$ DAP foi obtido por medição do perímetro com trena, dividido por 3,14. O dano à calçada foi definido por sim ou não. Para avaliar danos à copa, foram atribuídas três condições: normal (arquitetura normal da espécie), medianamente deformada (com copa levemente diferente da normal para a espécie, esboçando sinais leves de podas, porém, sem danos estruturais) e deformada (copa com arquitetura diferente do padrão da espécie, assimétrica ou exibindo sinais de podas drásticas, com comprometimento de pernada básica, braços primários e secundários). Quanto ao porte (altura média do indivíduo adulto por espécie), considerou-se os seguintes critérios: pequeno porte - até $6 \mathrm{~m}$, médio porte de 6 a $8 \mathrm{~m}$ e grande porte, acima de 8 metros (ELETROPAULO, 1995).

O espaço livre, sem pavimento, no entorno das árvores foi medido com trena.

O Índice de Diversidade de Shannom (IDS) foi calculado pela fórmula IDS= $\left(\sum p_{1} \cdot \log _{2} p_{1}\right)$, sendo $p_{1}$ a freqüência de indivíduos por espécie. Considera-se diversidade satisfatória para valores acima de 3 .

A origem das espécies foi definida segundo distribuição fitogeográfica das mesmas, classificadas em nativas ( $n$ ) e exóticas (e).

As larguras médias das ruas e calçadas foram colhidas em campo e confirmadas em planta digital.

A correlação entre os vários parâmetros foi feita através da correlação Linear de Pearson, onde o coeficente de Pearson ( $r$ ) pode variar de $-1 \mathrm{a}+1$, e quanto mais próximos destes valores, mais forte a associação entre as variáveis em estudo (AYRES et al, 2007). 
Os dados foram anotados em planilhas de campo, depois digitados em microcomputador no programa microsoft Excel, onde foram processados e apresentados em tabelas e gráficos.

\section{RESULTADOS E DISCUSSÃO}

As árvores encontradas nas calçadas das avenidas do centro do município de Cosmópolis estão distribuídas por 40 diferentes espécies (Tabela 1.)

A quantidade média de árvores por quarteirão foi de 23,92 indivíduos, sendo a média de árvores por $\mathrm{km}$ de calçada de 58,93 indivíduos e o total de árvores no centro de Cosmópolis, de 3.704 árvores distribuídas em 155 quarteirões.

A SBAU- Sociedade Brasileira de Arborização Urbana reconhece como um número ideal de árvores por km de calçada seja de pelo menos 100 indivíduos. Considerando existir em Cosmópolis 58,93 árvores por km de calçada, a quantidade é pouco mais que a metade do recomendado.

O Índice de Diversidade de Shannom - IDS é comumente utilizado para medir a diversidade de espécies, em função de suas frequencias. Utilizando-se os dados de frequencias da Tabela 1, encontrou-se um índice igual a 3,89, valor acima de 3 e portanto, por este índice a diversidade de espécies arbóreas encontradas nas calçadas do centro expandido de Cosmópolis é considerada alta. 
Tabela 1. Espécies encontradas no centro de Cosmópolis, SP, origens e freqüências.*

\begin{tabular}{|c|c|c|c|c|}
\hline Nome comum & Nome científico & $\begin{array}{l}\frac{\varepsilon}{0} \\
\text { 인 } \\
0\end{array}$ & 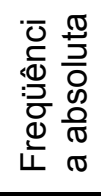 & 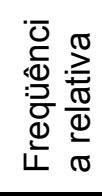 \\
\hline alecrim de campinas & Holocalyx glaziovii Taub. ex Glaz. & $\mathrm{n}$ & 3 & 1,03 \\
\hline alfeneiro & Ligustrum sinense Lour. & $\mathrm{e}$ & 5 & 1,72 \\
\hline angico & Anadenanthera macrocarpa (Benth.) Brenan & $\mathrm{n}$ & 1 & 0,34 \\
\hline araçá & Psidium cattleianum Sabine & $\mathrm{n}$ & 1 & 0,34 \\
\hline aroeira mansa & Schinus molle L. & $\mathrm{n}$ & 9 & 3,09 \\
\hline canelinha & Nectandra megapotamica (Sprengel) Mez. & $\mathrm{n}$ & 37 & 12,71 \\
\hline caramboleira & Averrhoa carambola L. & e & 1 & 0,34 \\
\hline cariota & Caryota urens L. & e & 2 & 0,69 \\
\hline seafortia & Archontophoenix cunninghamii H.Wendl. \& Drude & $\mathrm{e}$ & 1 & 0,34 \\
\hline cereja do rio grande & Eugenia involucrata DC. & e & 2 & 0,69 \\
\hline chapeu de praia & Terminalia catappa L. & e & 11 & 3,78 \\
\hline croton & Codiaeum variegatum $\mathrm{L}$. & e & 2 & 0,69 \\
\hline dama da noite & Cestrum nocturnum L. & $\mathrm{e}$ & 1 & 0,34 \\
\hline escovinha de grarrafa & Callistemon viminalis G. Don ex Loud & $\mathrm{e}$ & 1 & 0,34 \\
\hline espatódea & Spathodea campanulata P. Beauv. & $\mathrm{e}$ & 1 & 0,34 \\
\hline espirradeira & Nerium oleander L. & $\mathrm{e}$ & 1 & 0,34 \\
\hline falsa murta & Murraya exótica L. & e & 79 & 27,15 \\
\hline figueira & Ficus benjamina L. & e & 8 & 2,75 \\
\hline flamboyanzinho & Caesalpinia pulcherrima (L.) Sw. & e & 1 & 0,34 \\
\hline goiabeira & Psidium guajava L. & $\mathrm{n}$ & 1 & 0,34 \\
\hline gravioleira & Annona muricata L. & $\mathrm{e}$ & 1 & 0,34 \\
\hline ipê branco & Tabebuia roseo-alba (Ridl.) Sand. & $\mathrm{n}$ & 1 & 0,34 \\
\hline ipê rosa de El salvador & Tabebuia pentaphylla (L.) Hemsl. & $\mathrm{e}$ & 3 & 1,03 \\
\hline ipê roxo & Tabebuia impetiginosa (Mart. ex DC.) Standl & $\mathrm{n}$ & 1 & 0,34 \\
\hline jambeiro & Jambosa vulgaris DC. & $\mathrm{e}$ & 3 & 1,03 \\
\hline jerivá & Syagrus romanzoffiana (Cham.) Glassman & $\mathrm{n}$ & 24 & 8,25 \\
\hline leiteiro & Peschiera fuchsiaefolia (DC) Miers. & $\mathrm{n}$ & 1 & 0,34 \\
\hline magnólia amarela & Michelia champaca L. & $\mathrm{e}$ & 23 & 7,90 \\
\hline mirindiba rosa & Laphoensia glyptocarpa Koehne & $\mathrm{n}$ & 1 & 0,34 \\
\hline nespereira & Eriobotrya japonica (Thunb.) Lindl. & $\mathrm{e}$ & 4 & 1,37 \\
\hline oiti & Licania tomentosa (Benth.) Fritsch & $\mathrm{e}$ & 14 & 4,81 \\
\hline Pau-brasil & Caesalpinia echinata Lam. & $\mathrm{e}$ & 3 & 1,03 \\
\hline pingo de ouro & Duranta repens L. & $\mathrm{e}$ & 1 & 0,34 \\
\hline pinha & Anonna squamosa L. & $\mathrm{e}$ & 1 & 0,34 \\
\hline pitangueira & Eugenia uniflora L. & $\mathrm{n}$ & 2 & 0,69 \\
\hline quaresmeira & Tibouchina granulosa Cogn. & $\mathrm{n}$ & 2 & 0,69 \\
\hline resedá & Lagerstroemia indica L. & $\mathrm{e}$ & 26 & 8,93 \\
\hline romãzeira & Punica granatum L. & $\mathrm{e}$ & 1 & 0,34 \\
\hline sibipiruna & Caesalpinia peltophoroides Benth. & $\mathrm{n}$ & 9 & 3,09 \\
\hline unha de vaca & Bahuinia variegata $L$. & $\mathrm{e}$ & 2 & 0,69 \\
\hline
\end{tabular}

${ }^{*} \mathrm{n}$ - nativas, e - exóticas. 
Apesar do IDS ser considerado alto, pode-se visualizar pela Tabela 1 que a distribuição dos indivíduos pelas espécies é muito desuniforme. A Figura 2 também auxilia na constatação de que poucas espécies possuem um número elevado de indivíduos e a maioria das espécies possui poucos indivíduos. A média total de indivíduos por espécie é de 7,3 , o que evidencia elevada variância. Na categoria acima de $10 \%$, observa-se apenas duas espécies, somando 116 indivíduos (39,86\% do total de indivíduos), ou seja, uma média de 58 indivíduos por espécie. No extremo oposto, visualiza-se na freqüência de $0,34 \%$ a ocorrência de apenas 01 indivíduo por espécie. Na categoria entre 5 e $10 \%$, percebe-se apenas 3 espécies e 73 indivíduos, ou seja, uma média de 24,3 indivíduos por espécie. Entre 1 e $5 \%$ observa-se 11 espécies e 72 indivíduos, com uma média de 6,5 indivíduos por espécie, sendo esta categoria a mais equilibrada.

Estudando a arborização nas calçadas do centro de Penápolis, SP, Paiva e Dragoni (1997) encontraram 34 espécies arbóreas diferentes, com freqüências elevadas em poucas espécies. Silva (2005) observou 32 espécies nos bairros Antônio Zanaga I e II em Americana-SP, com alta freqüência de indivíduos em poucas espécies. Em Campos do Jordão-SP, Andrade (2002) encontrou 32 espécies arbóreas em vias públicas, com freqüências altas de indivíduos em poucas espécies. Milano (1987) levantou 93 espécies arbóreas nas ruas de Curitiba-PR, que apesar de ser aproximadamente três vezes a quantidade encontrada nos demais trabalhos, também observou altas freqüências em poucas espécies, sendo $92 \%$ do total de árvores distribuídas em apenas 18 espécies.

É recomendável para garantir uma diversidade elevada e conseqüentemente uma sustentabilidade ecológica maior, que se trabalhe no planejamento da arborização urbana com no mínimo 10 espécies e de preferência nativas. Sendo assim, as freqüências desejáveis deverão estar abaixo de 10\%, ou seja, cada espécie com menos de $10 \%$ do total de indivíduos (ELETROPAULO, 1995; BIONDI e ALTHAUS, 2005). 


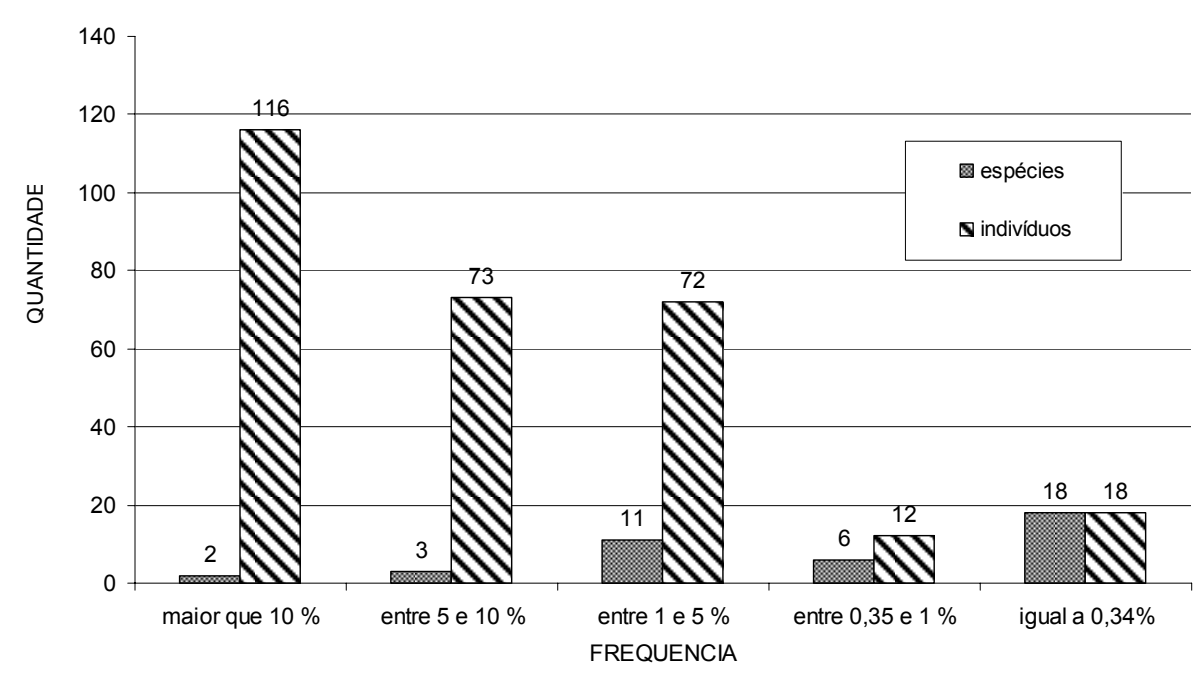

Figura 2. Distribuição das espécies por estrato de freqüência dos indivíduos encontrados nas calçadas do centro de Cosmópolis, SP.

Um parâmetro importante para o planejamento da arborização urbana é o porte das espécies, o que pode ser visualizado pela Figura 3, bem como a freqüência dos indivíduos e das espécies em cada um deles.

Pode-se observar pela Figura 3 que a maior quantidade de espécies $(47,5 \%)$ e indivíduos $(52,57 \%)$ está concentrada no grupo de grande porte. As espécies de pequeno porte representam apenas $17,5 \%$ do total e $29,55 \%$ dos indivíduos. As espécies de médio porte representam $35 \%$ das espécies e $17.8 \%$ dos indivíduos.

É recomendável a utilização de espécies compatíveis em porte com o espaço físico existente no sítio onde será plantada (ELETROPAULO, 1995; CPFL, 1998; SANTIN, 2008). Portanto, as espécies recomendadas para calçadas estão no grupo de pequeno e médio portes, sendo as de grande porte mais adequadas para plantio em áreas mais amplas como parques e bosques. Observa-se então que $47,5 \%$ das espécies e $53,57 \%$ dos indivíduos encontrados em Cosmópolis estão no grupo não recomendado para calçadas. 


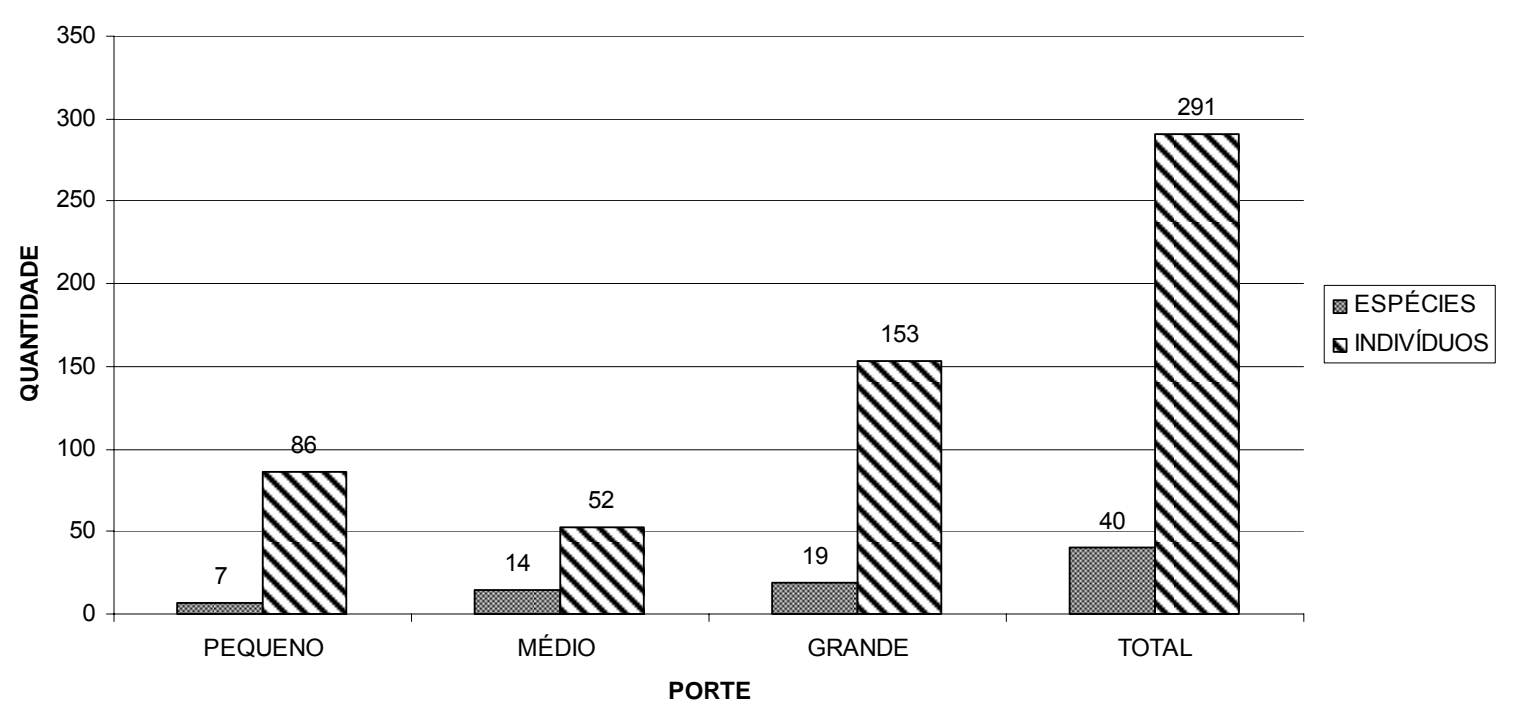

Figura 3. Freqüência de espécies e indivíduos por porte, de árvores ocorrentes nas calçadas do centro de Cosmópolis, SP.

Quanto à origem, percebe-se uma maior freqüência de espécies (57,5\%) e de indivíduos $(61,51 \%)$ exóticos quando comparados aos nativos, segundo Tabela 1 . Apesar da grande diversidade florística na região, ainda presencia-se o uso predominante de espécies exóticas na arborização urbana e mesmo em projetos de paisagismo. Esta situação é regra na maioria das cidades do País, observado em Penápolis, por Paiva e Dragoni (1997) onde $32,35 \%$ das espécies são nativas e 65,65\% exóticas, constatada também por Lizit (1993), em Manaus; Andrade (2002) em Campos do Jordão, SP; Meneghetti (2003) em Santos; Silva (2005) em Americana, SP; Couto (2006) no bairro Benfica, Rio de Janeiro, RJ; Silva (2002) em Uberlândia, MG; Alves et al. (2009) em Presidente Médici, RO; Silva et al. (2009) em Ponta Grossa, PR.

Não se deve excluir espécies exóticas de projetos de arborização e paisagismo urbanos, mas é importante atentar para o fato que estes projetos, além de cumprirem um papel estético, também devem cumprir papel funcional, promovendo serviços ambientais e interações com a fauna nativa, o que muitas vezes o uso de espécies exóticas põem em risco.

Os danos às calçadas provocados pelas árvores podem ser vistos na Figura 4. Existe um gradiente de dano, que aumenta com o aumento do porte da árvore. Observa-se que as espécies de pequeno porte não provocam danos às calçadas, o que era esperado. $\mathrm{Na}$ medida em que possuem estruturas radiculares e aéreas pequenas, não competem tanto em espaço com as outras estruturas e equipamentos urbanos, sendo mais adequadas aos pequenos espaços aéreos e subterrâneos disponíveis nestes sítios. 


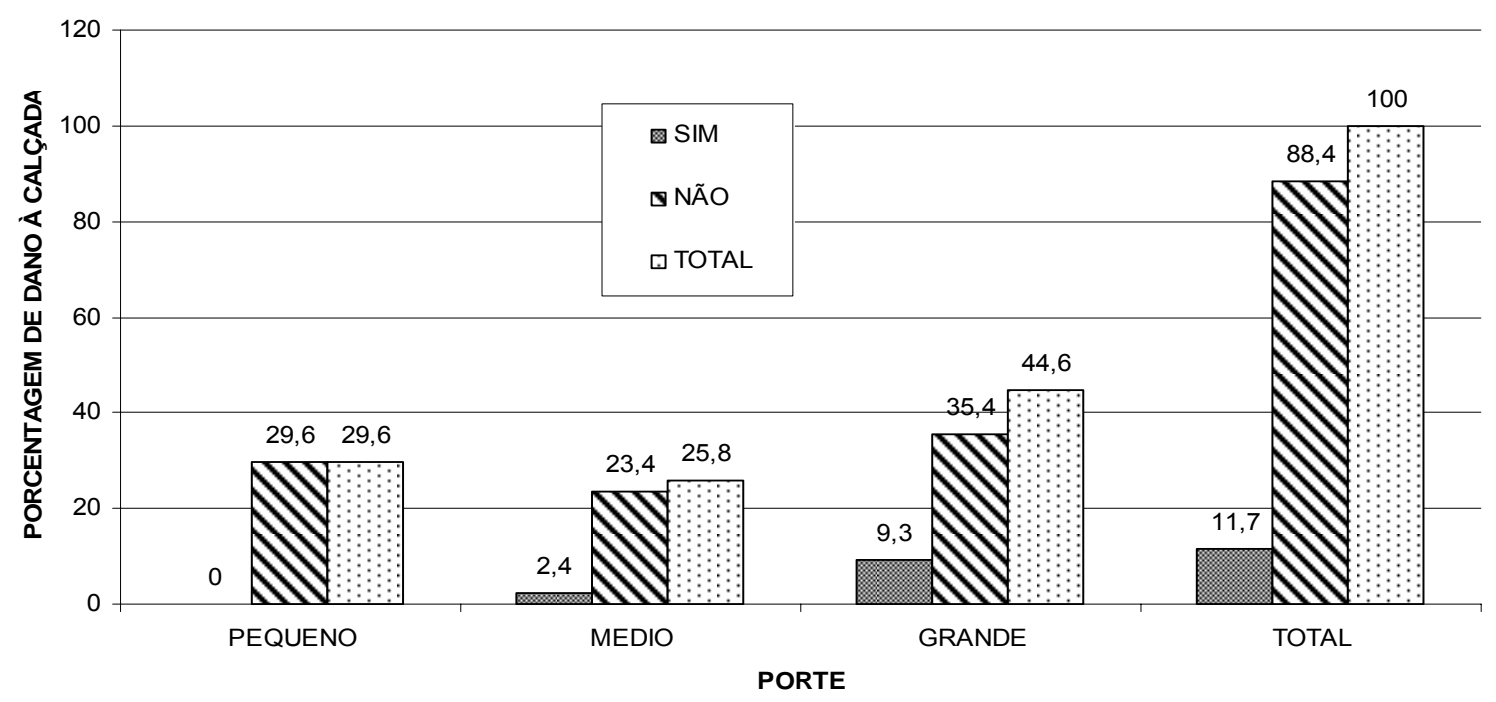

Figura 4. Danos às calçadas, por categoria de porte das espécies arbóreas ocorrentes no centro de Cosmópolis, SP.

Constatou-se a existência de correlação linear positiva entre DAP e porte das árvores e DAP e dano às calçadas, ou seja, as árvores com DAP maior têm porte maior e provocam maiores danos às calçadas, o que pode ser visto pela Figura 5.
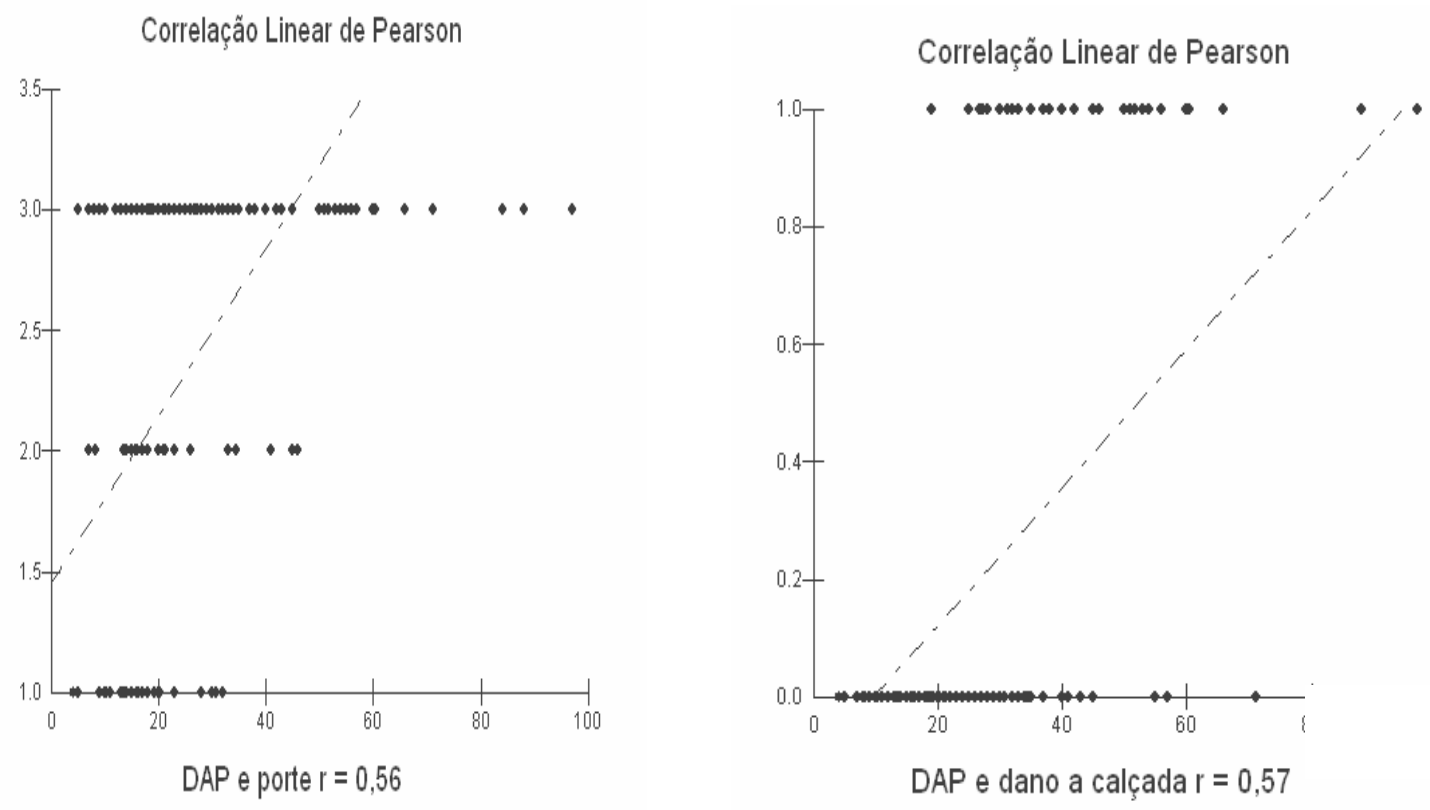

Figura 5. Correlação linear entre DAP, porte das árvores e dano provocado às calçadas encontradas no centro de Cosmópolis, SP.

Observou-se que os valores médios do espaço livre nas calçadas no entorno das árvores para seu estabelecimento e desenvolvimento é muito pequeno, ficando abaixo de $0,5 \mathrm{~m}^{2}$, o que agrava a situação das espécies com DAP maiores quanto ao dano à calçada. 
Muitas vezes, observou-se que os danos às calçadas não são provocados pelas raízes, mas pela ação mecânica do crescimento secundário (em diâmetro) do tronco das árvores, extrapolando a área livre sem pavimento.

Diferentemente das árvores encontradas no meio natural ou em áreas urbanas mais amplas, os exemplares arbóreos nas calçadas públicas sofrem as maiores pressões antrópicas, estando muito mais propensos à injúrias, principalmente físicas pela ação do homem. Percebe-se que apenas $14,4 \%$ dos exemplares estão com a arquitetura considerada normal para a espécie e 63,9 \% dos indivíduos estão com algum tipo de deformação da copa, mesmo que leve, ou seja, a estrutura dos ramos e galhos (pernadas básicas, braços primários e secundários) está ainda preservada, sendo possível a recuperação das formas arquitetônicas naturais de cada espécie (Figura 6). Em 21,6 \% dos indivíduos, as sucessivas e drásticas podas comprometeram irreversivelmente as copas das árvores.

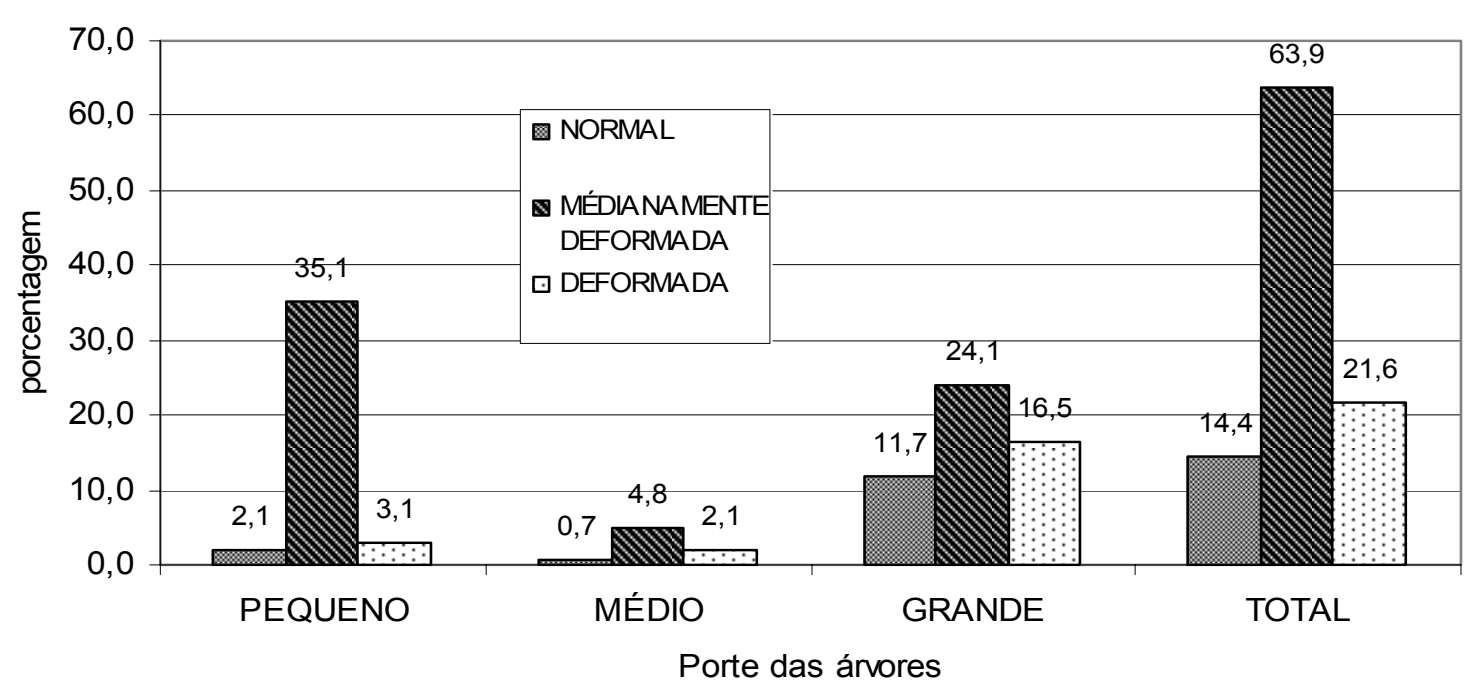

Figura 6. Estado físico das copas geral e por categoria de porte das espécies arbóreas encontradas nas calçadas no cento de Cosmópolis, SP.

Analisando-se o estado físico das copas pelo porte, observa-se que a porcentagem de árvores de pequeno e médio portes com copa normal é muito pequena. As espécies de grande porte apresentam mais indivíduos com arquitetura de copa normal do que as de pequeno e médio porte. A princípio, seria de se esperar que as copas das espécies de porte menor, apresentassem maior número de indivíduos com copa normal, mas estes dados corroboram o observado nas ruas e avenidas do município, onde a prática das podas de remodelagem das copas (tupiaria) é muito comum, transformada em prática cultural da população urbana, fato evidenciado pela inexistência de correlação linear entre porte e danos na copa. 
As espécies de pequeno porte apresentam o maior número de indivíduos com copa medianamente deformada, por serem as mais podadas como arbustos (tupiaria). As espécies de grande porte também apresentam elevado porcentual de indivíduos com copa medianamente deformada, superando as de médio porte.

Os indivíduos de espécies de grande porte aparecem em maior porcentual dentre as copas irreversivelmente deformadas, principalmente pelas podas realizadas em indivíduos localizados sob redes de distribuição de energia elétrica. As podas de remodelagem normalmente são leves, não deformando a estrutura das árvores (pernadas básicas e braços primários e secundários), e são aplicadas com maior freqüência nas espécies de pequeno porte, explicando a pequena ocorrência de indivíduos dentro do grupo das espécies com copa deformada. As espécies de médio porte que aparecem em segundo lugar entre as de copa deformada estão provavelmente sob rede elétrica, cuja altura de copa coincide com as fases da rede secundária.

Quanto aos aspectos do sítio, a largura média das calçadas encontradas no centro do município de Cosmópolis é de 3,00 m e a largura do leito de rodagem de $9 \mathrm{~m}$, totalizando 15 metros a largura média total da via pública, propiciando espaço adequado à implantação de projetos de arborização viária.

\section{CONCLUSÕES}

Embora a diversidade de espécies encontrada nas ruas do centro de Cosmópolis seja considerada alta, ocorre uma distribuição heterogênea das frequencias, existindo poucas espécies com muitos indivíduos e muitas espécies com poucos indivíduos.

As espécies de grande porte predominam, bem como as de origem exótica.

A maioria dos indivíduos apresenta algum tipo de dano na arquitetura de sua copa.

Existe correlação positiva entre DAP e dano às calçadas.

O espaço livre permeável no entorno das árvores nas calçadas é muito pequeno.

A área em estudo apresenta pouco mais da metade da quantidade de árvores recomendada como ideal pela SBAU.

É de fundamental importância que os gestores públicos do município de Cosmópolis incluam no planejamento urbano medidas que possam adequar a arborização de suas áreas públicas, para que possam cumprir com suas funções ecológicas e melhorarem as condições ambientais e a qualidade de vida de sua população. 


\section{REFERÊNCIAS BIBLIOGRÁFICAS}

AYRES, M.; AYRES JR., M; AYRES, D.L; SANTOS, A.A. Bioestat: aplicações estatísticas nas áreas de ciências biológicas e médicas. Belém: Sociedade Civil Mamirauá, MCT-CNPq, 2007.

ALVES, S.S.; SANTOS, M. C. V.; CHAGAS, V. J. Análise qualitativa e quantitativa da arborização urbana, no município de Presidente Médici, RO. In: CONGRESSO BRASILEIRO DE ARBORIZAÇÃO URBANA, 13, 2009, Rio Branco. Anais. Rio Branco: Sociedade Brasileira de Arborização Urbana, 2009.

ANDRADE, T. O. Inventário e análise da arborização viária da estância turística de Campos do Jordão, SP. 2002. Dissertação (Mestrado em Agronomia - Fitotecnica) - Escola Superior de Agricultura Luiz de Queiroz - ESALQ USP, Piracicaba, SP, 2002.

BIONDI, D. ; ALTHAUS, M. Árvores de Rua de Curitiba: Cultivo e Manejo. Curitiba: FUPEF, 2005.

COUTO, C.S. Inventário e diagnóstico da arborização urbana do bairro de Benfica, município do Rio de Janeiro, RJ. 2006. 44 p. Monografia (Graduação em Engenharia Florestal) - Instituto de Florestas, Universidade Federal Rural do Rio de Janeiro, Seropédica, RJ, 2006.

ELETROPAULO. Guia de planejamento e manejo da arborização urbana. São Paulo: Eletropaulo, Cesp, CPFL, 1995. 40 p.

GONÇALVES, W. Árvores para o ambiente urbano. Viçosa: Aprenda fácil, 2004.

LIZIT, A. C. Análise e avaliação do manejo da arborização urbana pública da cidade de Manaus. Dissertação (Mestrado em Biologia Tropical e Recursos Naturais) - Instituto Nacional de Pesquisas da Amazônia, Manaus, 1993.

LORENZI, H. Árvores Brasileiras: manual de identificação e cultivo de plantas arbóreas nativas do Brasil. 2. ed. Nova Odessa, SP: Editora Plantarum, 1998. 352 p.

MENEGHETTI, G. I. P. Estudo de dois métodos de amostragem para inventário da arborização de ruas dos bairros da orla marítima do município de Santos, SP. 
Dissertação (Mestrado em Recursos Florestais) - Departamento de Ciências Florestais, Escola Superior de Agricultura Luiz de Queiroz - ESALQ USP, Piracicaba, SP, 2003.

MILANO, M. S. O planejamento da arborização, as necessidades de manejo e tratamentos culturais das árvores de ruas de Curitiba, PR. Floresta, v.17, n.1/2, p.15-21, jun./dez.1987.

MILLER, R. W. Urban Forestry: planning and managing urban grenspaces. Upper Saddle River, New Jersey, USA: Prentice Hall, 1996, 502 p.

PAIVA, A. V.; DRAGONI, V. F. Projeto de inventário, diagnóstico e rearborização urbana da região central do município de Penápolis, SP. In: ENCONTRO NACIONAL SOBRE ARBORIZAÇÃO URBANA, 7., 1997, Belo Horizonte,. Anais. Belo Horizonte: Sociedade Brasileira de Arborização Urbana, 1997. p. 80.

PAIVA, H. N.; GONÇALVES, W. Florestas urbanas: planejamento para melhoria da qualidade de vida. Viçosa: Aprenda Fácil, 2002. 177p.

PRADO, H. Os solos no Estado de São Paulo: mapas pedológicos. Piracicaba: Helio Prado, 1997. 205 p.

SANTIN, D. A. (Coord.) Guia de Arborização Urbana de Campinas. Prefeitura Municipal de Campinas, SP, Campinas: Gráfica e Editora Lince, 2008, 70 p.

SILVA, E. M. Estudo da arborização urbana do bairro Mansour, na cidade de UberlândiaMG. Caminhos de Geografia, Uberlândia, MG, v. 3, n. 5., p. 73-83, 2002.

SILVA, L. F. Situação da arborização viária e proposta de espécies para os bairros Antônio Zanaga I e II, da cidade de Americana/SP. 2005. Dissertação (Mestrado em Fitotecnia) - Escola Superior de Agricultura Luiz de Queiroz, ESALQ-USP, Piracicaba, SP, 2005.

SILVA, R. K.; CARVALHO, S. M.; VILELA, J. C.Análise quantitativa da arborização urbana viária dos bairros Olarias e Estrela na cidade de Ponta Grossa, PR. In: CONGRESSO BRASILEIRO DE ARBORIZAÇÃO URBANA, 13. , 2009, Rio Branco, AC. Anais. Rio Branco: Sociedade Brasileira de Arborização Urbana, 2009. 
COUTO, H. T.Z; RACHID, C. Estudo da eficiência de dois métodos de amostragem de árvores de rua na cidade de São Carlos - SP. Scientia Forestalis, Piracicaba, n. 56, p. 5968, 1999. 